\title{
The noradrenergic symptom cluster: clinical expression and neuropharmacology
}

This article was published in the following Dove Press journal:

Neuropsychiatric Disease and Treatment

2 June 2011

Number of times this article has been viewed

\author{
Pierre Blier ${ }^{1}$ \\ Mike Briley ${ }^{2}$ \\ 'Institute of Mental Health Research, \\ University of Ottawa, Ottawa, \\ Ontario, Canada; ${ }^{2} \mathrm{NeuroBiz}$ \\ Consulting and Communication, \\ Castres, France
}

\begin{abstract}
Signs and symptoms of depression can be linked to one or more monoaminergic systems, specifically the norepinephrine (NE), the dopamine (DA), and the serotonin (5-HT) systems. In particular, the modulation of energy, vigilance, and arousal can be directly linked to the NE system. There is, however, a great deal of overlap in the modulation of the symptoms of depression between these monoaminergic systems. There are considerable reciprocal interactions between the NE, DA, and the 5-HT systems. When using a selective serotonin reuptake inhibitor (SSRI), for example, 5-HT transmission is enhanced, but at the same time there is a dampening of the activity of $\mathrm{NE}$ and DA neurons through inhibitory $5-\mathrm{HT}_{2 \mathrm{~A}}$ and $5-\mathrm{HT}_{2 \mathrm{C}}$ receptors, respectively. This could explain the residual symptoms of fatigue, lack of energy, and anhedonia, often seen after patients present an overall positive response to a SSRI. Using a dual 5-HT and NE reuptake inhibitor (SNRI), such as milnacipran, would result in an additional increase in NE activity. Futhermore, inhibiting NE reuptake increases DA availability in the frontal cortex since DA is mainly cleared by the NE transporters in several brain regions. A risk inherent in increased NE activity is that of provoking anxiety. This is avoided however by the attenuation of the phasic reactivity of the firing of NE neurons through prolonged administration of SSRI and SNRI.
\end{abstract}

Keywords: norepinephrine, dopamine, serotonin, residual symptoms, norepinephrine paradox

\section{Introduction}

Noradrenergic pathways in the brain originate mainly in the locus coeruleus and project to the cortex, limbic regions, and hindbrain. They are involved in the regulation of energy levels, vigilance, reactivity, and executive function. Noradrenergic stimulation dampens noise in both excitatory and inhibitory circuits thus enhancing signal to noise in the target areas. ${ }^{1}$

The functions of norepinephrine (NE) and dopamine (DA) are closely linked. The DA system is extremely complex due to the multitude of DA receptor subtypes, their locations, and functions. The nigrostriatal DA pathway, which projects from the substantia nigra to the basal ganglia, is part of the extrapyramidal system and plays a key role in regulating movement. DA deficiency can thus result in Parkinsonism with tremor, rigidity, and akinesia/bradykinesia. The mesolimbic DA pathway originates from dopaminergic cell bodies in the ventral tegmental area of the brainstem and projects to limbic regions of the brain. These pathways play an important role in emotional behavior, such as pleasurable sensations, the euphoria experienced with drugs of abuse, and the delusions and hallucinations of psychosis. Mesocortical DA projections mediate cognitive functions, such as
Endowed Chair and Director, Mood

Disorders Research, University of

Ottawa Institute of Mental Health

Research (IMHR), I I 45 Carling Avenue,

Room 64II, Ottawa, ON KIZ 7K4

Canada

$\mathrm{Tel}+|6| 3722652 \mid$

$\mathrm{Fax}+1613761-3610$

Email pierre.blier@rohcg.on.ca
Neuropsychiatric Disease and Treatment 20I I:7 (Suppl I) I5-20 5

Dovepress

(c) 20II Blier and Briley, publisher and licensee Dove Medical Press Ltd. This is an Open Access article

DOI: 10.21471 NDT.S19613

which permits unrestricted noncommercial use, provided the original work is properly cited. 
verbal fluency, focus, serial learning, executive functioning, focusing and sustaining attention, prioritizing behavior, and modulating social behavior. ${ }^{1}$

The effects of NE, serotonin (5-HT), and DA overlap in the brain and all three transmitters are implicated in the symptoms of depression. The three neurotransmitters are involved in mood, emotion, cognition, and chronic pain. Symptoms associated with vigilance, arousal, interest, and energy are most closely associated with NE neurotransmission while impulsivity is associated with 5-HT neurotransmission, and symptoms associated with drive are related to DA neurotransmission. Thus, depressive symptoms may result from dysfunction of any or all of the monoamine neurotransmitter systems. ${ }^{1}$

\section{Residual symptoms}

Remission, usually defined as a score of 7 or less on the Hamilton depression rating scale (HAMD) or 10 or less on the Montgomery-Asberg depression rating scale (MADRS), does not necessarily mean a total absence of all symptoms. Residual symptoms are present in $30 \%$ to $50 \%$ of patients in remission. In addition to the reduced quality of life this causes, relapse rates are 3 to 6 times higher in patients with residual symptoms. ${ }^{2,3}$

The nature of the residual symptoms can vary depending on the nature of the initial depression and antidepressant used $^{4}$ but in general, fatigue (both mental and physical), concentration difficulties, decreased interest or pleasure, cognitive impairment, and anxiety are among the most common residual symptoms. ${ }^{3,5}$ For example, in a study of 215 patients with major depressive disorder who received fluoxetine for 8 weeks, 108 were found to be in remission (HAMD $\leq 7) .{ }^{6}$ Of these, however, only $18 \%$ had no threshold or subthreshold symptoms of major depression, while $26 \%$ had one residual symptom, and over half (57\%) still had 2 or more symptoms. The question can be asked as to whether these remaining symptoms are true residual symptoms or iatrogenic symptoms caused by the antidepressants used to treat the disorder. ${ }^{2,3}$ In order to answer this question it is necessary to examine the interaction between 5-HT and NE and DA neurotransmission.

\section{Interaction between 5-HT and NE neurotransmission}

5-HT projections from the raphe nucleus to the locus coeruleus impose a tonic inhibitory tone on the firing of NE neurons. When this inhibition is removed, NE firing and release are increased. This has been shown in animal studies where brain 5-HT levels were reduced by administration of the 5-HT synthesis inhibitor, p-chlorophenylalanine ${ }^{7}$ or by lesion of the raphe nucleus using the specific 5-HT neuron toxin, 5,7-dihydroxytryptamine (5,7-DHT). ${ }^{8}$ In both cases removal of the serotonergic influence on the locus coeruleus led to a significant increase in firing of the NE neurons.

If the serotonergic inhibition of NE neurotransmission is increased, as during treatment with a selective serotonin reuptake inhibitor (SSRI), NE firing and release are decreased. Sustained administration of the SSRI, citalopram, for 21 days, (20 mg/kg/d sc using osmotic minipumps) produced a progressive decrease in spontaneous firing activity of NE neurons in the locus coeruleus. ${ }^{9}$ Similarly, subacute and long-term treatment with the SSRI, escitalopram, decreased NE neuronal firing. Blockade of this effect by selective antagonists showed that the effect was mediated by the $5-\mathrm{HT}_{2 \mathrm{~A}}$ receptor. $^{7}$

The effects of chronic administration of citalopram are also seen on the levels of extracellular NE in the brain. Brain microdialysis was used to determine the extracellular $\mathrm{NE}$ in conscious rats. In rats treated daily for 14 days with citalopram (10 mg/kg/day sc), NE levels in the dialysate showed a significant decrease in the basolateral nucleus of the amygdala. ${ }^{10}$

\section{Interaction between 5-HT and DA neurotransmission}

In addition to its tonic inhibition of NE transmission, 5-HT also inhibits the firing of DA neurons. Selective lesion of 5-HT neurons by 5,7-DHT enhanced the firing activity of DA neurons in the ventral tegmental area by $36 \%$, indicating the presence, under normal conditions, of a tonic inhibitory effect of 5-HT on these DA neurons. ${ }^{11}$ Sustained administration of escitalopram robustly decreased the firing rate of DA neurons. This inhibition was reversed by a selective $5-\mathrm{HT}_{2 \mathrm{C}}$ receptor antagonist. ${ }^{7}$

Thus 5-HT exerts a tonic inhibition on NE neurons through $5-\mathrm{HT}_{2 \mathrm{~A}}$ receptors and a tonic inhibition of DA neurons through $5-\mathrm{HT}_{2 \mathrm{C}}$ receptors.

\section{Residual or iatrogenic symptoms?}

SSRI treatment results in a sustained increase of 5-HT activity and thus an increased inhibitory tone which leads to a decrease of both NE and DA neurotransmission. These two neurotransmitters are closely implicated in the regulation of the many frequent residual symptoms, namely, fatigue, decreased concentration, decreased interest or pleasure, cognitive impairment, and anxiety. Thus it is possible that 
these "residual" symptoms could be, at least in part, the result of SSRI treatment and thus "iatrogenic".

\section{The effects of milnacipran}

The serotonin norepinephrine reuptake inhibitor (SNRI), milnacipran, is unique in as much as it blocks the reuptake of both 5-HT and NE with similar affinity without any effects on postsynaptic receptors. ${ }^{12,13}$ As with SSRIs, milnacipran inhibits the firing of NE neurons in the locus coeruleus. ${ }^{14}$ Unlike SSRIs, however, milnacipran also blocks the reuptake of NE. Microdialysis studies have shown that, unlike SSRIs, which after chronic administration increase 5-HT levels ${ }^{7,9,10}$ but decrease NE levels, both acute and subacute administration of milnacipran increase extracellular levels of both 5-HT and NE. ${ }^{15,16}$

Although it has no affinity with the DA transporter (and does not block the reuptake of DA), ${ }^{12,13}$ milnacipran increases DA levels, as well as NE and 5-HT levels, in the frontal cortex. ${ }^{16,17}$ Although the exact nature of this effect has not yet been determined a probable mechanism can be proposed. The NE transporter has similar affinities for NE and DA. ${ }^{18}$ Since DA is relatively abundant compared with DA transporters in the prefrontal cortex ${ }^{19}$ it can be taken up non-selectively by NE transporters in this region ${ }^{20}$ and co-released with NE. ${ }^{21}$ The selective NE uptake inhibitors, reboxetine and atomoxetine, which have no affinity with the DA transporter, have been shown to increase extracellular DA levels as well as NE levels in the prefrontal cortex, but not in the nucleus accumbens. ${ }^{22,23}$ The inhibition of the NE transporter by milnacipran therefore results in an increase in the extracellular levels of both NE and DA.

In contrast to the SSRIs, milnacipran increases extracellular levels of NE and DA which may compensate for the decreased firing of NE neurons. Clinically this could translate into less reduced residual (iatrogenic?) symptoms compared with treatment with SSRIs. No studies have yet analyzed the comparative frequencies of residual symptoms with milnacipran and SSRIs. However a recent study comparing the SSRI, escitalopram with the SNRI, duloxetine, found that patients on the SNRI had greater improvement in cognitive function in the remission phase, and in the recovery phase. ${ }^{24}$

\section{The noradrenergic paradox}

There is strong evidence of a close relationship between NE stimulation and the induction of anxiety states. ${ }^{25}$ If milnacipran increases synaptic levels of NE (and DA) why does it not increase anxiety?
The effects of NE neurotransmission on the function of the prefrontal cortex can be described by an inverted $U$ shape (Figure 1). ${ }^{26}$ Very low levels of NE (and DA) transmission result in cognitive impairment, inattention, and drowsiness. Optimal levels of NE neurotransmission lead to enhanced cognitive performance and executive functions that guide behavior, thought, and affect (Table 1). Very high levels of NE stimulation produce cognitive impairment, anxiety, and even dysphoric psychosis. Thus one might expect chronic NE reuptake inhibition with milnacipran to increase anxiety symptoms. This, however, does not happen. ${ }^{27}$ Indeed several studies have shown that milnacipran decreases anxiety both in animal models of anxiety, ${ }^{28}$ in anxio-depressive ${ }^{29}$ and anxio-schizophrenic patients. ${ }^{30}$

A possible reason is that there are two types of NE firing pattern in the brain: tonic and phasic. ${ }^{31}$ Tonic firing is the steady-state, background firing that occurs at rest. It correlates with behavioral arousal at rest (awake, alert). Mechanistically it involves exocytotic release of $\mathrm{NE}$ at the nerve terminal. Phasic reactivity, on the other hand, occurs in response to a stimulus. It correlates with threat or stress-induced anxietylike behavior or, in extreme cases, a panic attack. It can last from seconds to minutes or longer. It increases vigilance (hypervigilance), enhances sensorimotor reflex responses, increases acoustic startle reflex, and reduces immobility and facilitates active escape behaviors (fight or flight response to an aversive stimulus). It is a result of robust increases in $\mathrm{NE}$ neuron firing. A certain amount of phasic reactivity is necessary for survival, but too much (as in anxiety disorders and anxious depression and panic disorder) is maladaptive.

In the depressed state, with no threatening stimulus, tonic NE activity (exocytotic release) at rest is low. The low

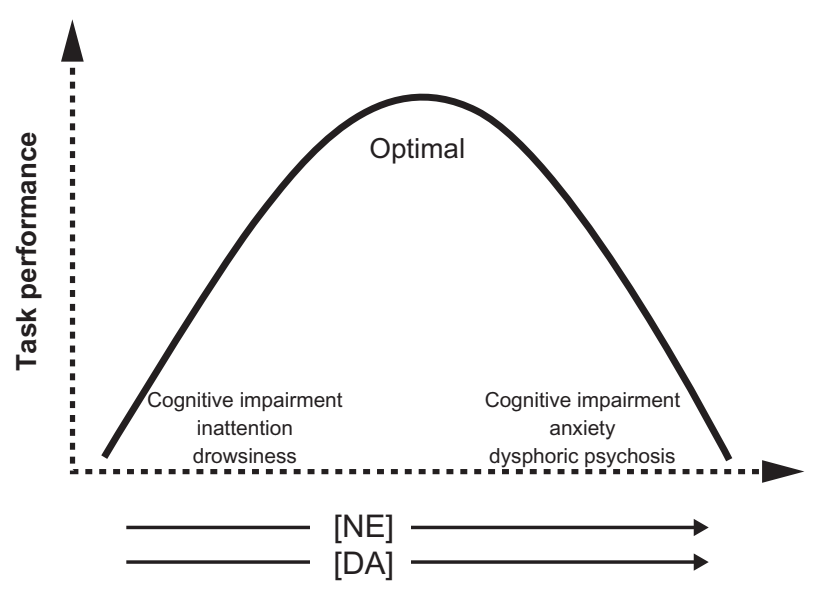

Figure I Norepinephrine (NE) and dopamine (DA) neurotransmission in the prefrontal cortex and executive function. NE and DA in arrows represent increasing levels of stimulation. 
Table I Executive function in the prefrontal cortex and its effect on behavior, thought and affect

\section{Executive function in the prefrontal cortex}

- Regulates working memory (maintains task relevant information when stimuli are no longer present in the environment)

- Inhibits inappropriate responses (impulse control)

- Suppresses distractions (attention)

- Promotes organization and planning

- Stimulates purposeful behavior (implementation)

- Integrates cognition with emotion

Summarized from references 26,37 .

basal firing rate of NE neurons combined with an efficient reuptake may lead to very low extracellular NE levels in the prefrontal cortex resulting in fatigue, somnolence, and cognitive impairment. ${ }^{31-33}$ This corresponds to the left-hand end of the inverted-U curve (Figure 1).

In the face of acute stress or a threatening stimulus, NE neurons (with low tonic, baseline levels of NE exerting only a minimal inhibition, via the somatodendritic $\alpha_{2}$-receptors, on the firing of neurons in the locus coeruleus) would respond with very high phasic reactivity (a sharp increase in neuronal firing). This important increase in firing would greatly increase extracellular NE to levels corresponding to the far right-hand end of the inverted-U curve (Figure 1).
Clinically this would produce cognitive impairment, anxiety/ panic, and dysphoric psychosis. ${ }^{14,31-33}$

Although it increases NE (and DA) neurotransmission in the prefrontal cortex, milnacipran does not cause anxiety. This NE paradox is explained by the different adaptation to chronic drug treatment of the two types of firing. ${ }^{31}$

\section{The effect of acute and long-term milnacipran treatment on $5-\mathrm{HT}$ and NE neurotransmission}

Acute treatment with milnacipran (Figure $2 \mathrm{a}$ ) results in increased synaptic concentrations of 5-HT but decreased firing of the 5-HT neurons in the raphe nucleus possibly as a result of increased stimulation of the inhibitory somatodendritic autoreceptors. Long-term treatment results in a further increase in synaptic concentrations of 5-HT due to desensitization of terminal autoreceptors controlling the release of 5-HT. Neuronal firing has been shown to recover to normal levels in the presence of SSRI or milnacipran. ${ }^{14}$ The ensuing enhanced 5-HT neurotransmission may thus contribute to its antidepressant effect. The increased 5-HT transmission by SSRI would also act to inhibit NE neurotransmission. Decreased NE phasic reactivity (NE firing) would lead to an anxiolytic effect, but the decreased tonic NE activity
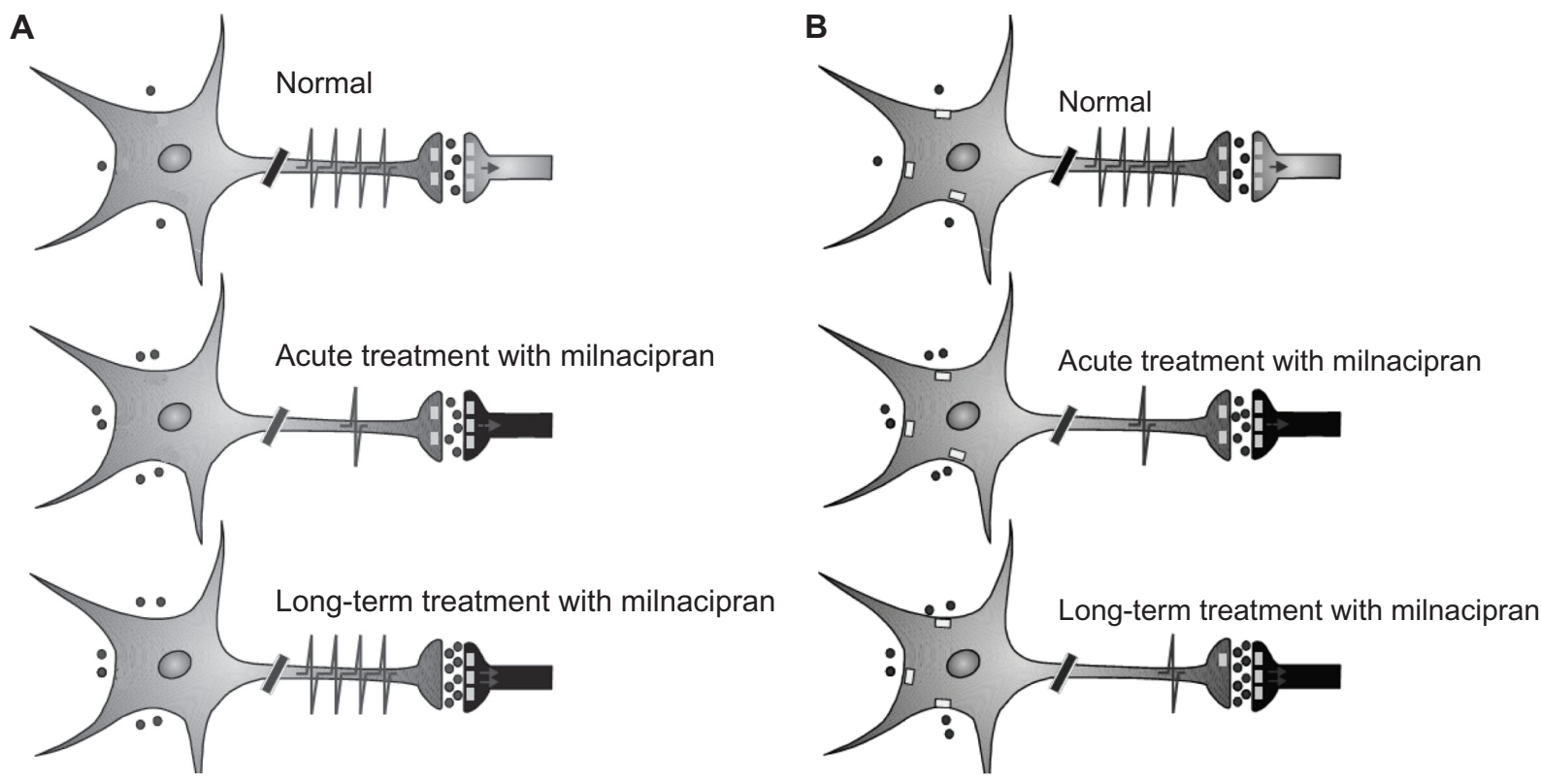

Figure 2 Scheme of the activity of 5-HT (A) and norepinephrine (NE) (B) neurotransmission during treatment with milnacipran. A) 5-HT system. Acute treatment with milnacipran results in a decreased firing of 5-HT neurons from the raphe nucleus possibly due in part to increased stimulation of somatodendritic autoreceptors. Longterm treatment with milnacipran results in a full recovery in the firing rate of 5-HT neurons in the presence of milnacipran thereby leading to a net increase in 5-HT neurotransmission. Contributing to this enhancement are: I) the normalized firing rate of 5-HT neurons in the presence of milnacipran 2) the desensitization of the terminal $5-\mathrm{HT}_{\mathrm{IB}}$ autoreceptor, and 3) the desensitization of the $\alpha_{2}$-adrenergic heteroreceptors on 5-HT terminals. B) NE system. Acute treatment with milnacipran results in increased synaptic concentrations of NE but decreased firing of the NE neurons of the locus coeruleus due to increased stimulation of the somatodendritic $\alpha_{2}$-adrenergic autoreceptors. Long-term treatment with milnacipran results in a further increase in synaptic concentrations of NE due to desensitization of presynaptic autoreceptors. The somatodendritic $\alpha_{2}$-adrenergic autoreceptors do not desensitize. 
(NE release) could potentially lead to side effects (or residual symptoms) such as, fatigue, apathy, low interest, indifference, and cognitive dulling.

Treatment with milnacipran, however, will also act upon NE neurotransmission. Acute treatment will (Figure 2b) result in increased synaptic concentrations of $\mathrm{NE}$ but decreased firing of the NE neurons in the locus coeruleus through stimulation of inhibitory somatodendritic autoreceptors. Long-term treatment results in a further increase in synaptic concentrations of NE due to desensitization of terminal autoreceptors (controlling the release of NE). The enhanced NE neurotransmission may thus contribute to the antidepressant effect. In contrast to terminal $\alpha_{2}$-adrenergic autoreceptors controlling NE release, long-term blockade of the NE transporter does not desensitize somatodendritic $\alpha_{2}$-adrenergic autoreceptors which control NE firing ${ }^{34,35}$ so that the firing of the NE neurons remains suppressed. This phenomenon has been recently reviewed. ${ }^{36}$ This decreased phasic NE reactivity may contribute to the anxiolytic effect. The enhanced tonic NE activity however, should potentially reduce the risk of the long-term side effects (residual symptoms?) seen with SSRIs. In addition the low phasic NE reactivity may protect against the acute stress-induced anxiety or panic attacks following long-term NE reuptake inhibition in part also due to the desensitization of excitatory $\beta$-adrenergic receptors on postsynaptic neurons.

\section{Conclusion}

The signs and symptoms of depression are modulated by changes in NE, 5-HT, and DA neurotransmission. Reduced NE activity may contribute to symptoms such as fatigue, apathy, low interest, indifference, and decreased cognitive performance.

SSRIs may contribute to residual symptoms by dampening $\mathrm{NE}$ and DA neuronal activity. Milnacipran, which increases $\mathrm{NE}$ (and DA) as well as 5-HT neurotransmission, is expected to improve depressive symptoms without causing iatrogenic residual symptoms. Milnacipran increases tonic NE activity, while attenuating phasic NE reactivity. Its action on the three monoamine neurotransmitters contributes to its antidepressant action while its attenuation of phasic NE reactivity may decrease the risk of anxiety.

\section{Disclosures}

Dr Pierre Blier has received research support from, spoken for, or sits on advisory boards for the following companies: AstraZeneca, Biovail, Bristol-Myers Squibb, Eli Lilly, Cyberonics, Janssen-Ortho, Jazz Pharmaceuticals, Pierre Fabre Medicaments, Labopharm, Lundbeck/Takeda, Merck,
Schering-Plough, Sanofi-Synthélabo, Servier, Shire and Wyeth. Dr Mike Briley is a consultant for Pierre Fabre Médicament, Asahi Kasei Pharma, Germania Pharmaceutica, Janssen Pharmaceutica, and Cypress BioScience.

\section{References}

1. Stahl SM. Stahl's Essential Psychopharmacology: Neuroscientific Basis and Practical Applications. 3rd ed. Cambridge, UK: Cambridge University Press; 2008.

2. Nutt D, Demyttenaere K, Janka Z, et al. The other face of depression, reduced positive affect: the role of catecholamines in causation and cure. J Psychopharmacol. 2007;21:461-471.

3. Trivedi MH, Hollander E, Nutt D, Blier P. Clinical evidence and potential neurobiological underpinnings of unresolved symptoms of depression. J Clin Psychiatry. 2008;69:246-258.

4. Kurian BT, Greer TL, Trivedi MH. Strategies to enhance the therapeutic efficacy of antidepressants: targeting residual symptoms. Expert Rev Neurother. 2009;9:975-984.

5. Conradi HJ, Ormel J, de Jonge P. Presence of individual (residual) symptoms during depressive episodes and periods of remission: a 3-year prospective study. Psychol Med. 2011. In press.

6. Nierenberg AA, Keefe BR, Leslie VC, et al. Residual symptoms in depressed patients who respond acutely to fluoxetine. J Clin Psychiatry. 1999;60:221-225.

7. Dremencov E, El Mansari M, Blier P. Noradrenergic augmentation of escitalopram response by risperidone: electrophysiologic studies in the rat brain. Biol Psychiatry. 2007;61:671-678.

8. Haddjeri N, de Montigny C, Blier P. Modulation of the firing activity of noradrenergic neurones in the rat locus coeruleus by the 5-hydroxtryptamine system. Br J Pharmacol. 1997;120:865-875.

9. Szabo ST, de Montigny C, Blier P. Progressive attenuation of the firing activity of locus coeruleus noradrenergic neurons by sustained administration of selective serotonin reuptake inhibitors. Int $J$ Neuropsychopharmacol. 2000;3:1-11.

10. Kawahara Y, Kawahara H, Kaneko F, Tanaka M. Long-term administration of citalopram reduces basal and stress-induced extracellular noradrenaline levels in rat brain. Psychopharmacology (Berl). 2007;194:73-81.

11. Guiard BP, El Mansari M, Merali Z, Blier P. Functional interactions between dopamine, serotonin and norepinephrine neurons: an in-vivo electrophysiological study in rats with monoaminergic lesions. Int J Neuropsychopharmacol. 2008;11:625-639.

12. Moret C, Charveron M, Finberg JP, Couzinier JP, Briley M. Biochemical profile of midalcipran (F 2207), 1-phenyl-1-diethylaminocarbonyl-2-aminomethyl-cyclopropane ( $Z$ ) hydrochloride, a potential fourth generation antidepressant drug. Neuropharmacology. 1985;24:1211-1219.

13. Koch S, Hemrick-Luecke SK, Thompson LK, et al. Comparison of effects of dual transporter inhibitors on monoamine transporters and extracellular levels in rats. Neuropharmacology. 2003;45:935-944.

14. Mongeau R, Weiss M, de Montigny C, Blier P. Effect of acute, short- and long-term milnacipran administration on rat locus coeruleus noradrenergic and dorsal raphe serotonergic neurons. Neuropharmacology. 1998;37:905-918.

15. Moret C, Briley M. Effects of milnacipran and pindolol on extracellular noradrenaline and serotonin levels in guinea pig hypothalamus. J Neurochem. 1997;69:815-822.

16. Kitaichi Y, Inoue T, Izumi T, Nakagawa S, Kato A, Koyama T. Subchronic milnacipran treatment increases basal extracellular noradrenaline concentrations in the medial prefrontal cortex of rats. Eur J Pharmacol. 2005;520:37-42.

17. Kitaichi Y, Inoue T, Nakagawa S, Izumi T, Koyama T. Effect of milnacipran on extracellular monoamine concentrations in the medial prefrontal cortex of rats pre-treated with lithium. Eur J Pharmacol. 2005;516:219-226. 
18. Raiteri M, Del Carmine R, Bertollini A, Levi G. Effect of sympathomimetic amines on the synaptosomal transport of noradrenaline, dopamine and 5-hydroxytryptamine. Eur J Pharmacol. 1977;41:133-143.

19. Sesack SR, Hawrylak VA, Matus C, Guido MA, Levey AI. Dopamine axon varicosities in the prelimbic division of the rat prefrontal cortex exhibit sparse immunoreactivity for the dopamine transporter. J Neurosci. 1998;18:2697-2708.

20. Yamamoto BK, Novotney S. Regulation of extracellular dopamine by the norepinephrine transporter. J Neurochem. 1998;71:274-280.

21. Devoto P, Flore G, Pani L, Gessa GL. Evidence for co-release of noradrenaline and dopamine from noradrenergic neurons in the cerebral cortex. Mol Psychiatry. 2001;6:657-664.

22. Linnér L, Endersz H, Ohman D, Bengtsson F, Schalling M, Svensson TH. Reboxetine modulates the firing pattern of dopamine cells in the ventral tegmental area and selectively increases dopamine availability in the prefrontal cortex. J Pharmacol Exp Ther. 2001;297:540-546.

23. Bymaster FP, Katner JS, Nelson DL, et al. Atomoxetine increases extracellular levels of norepinephrine and dopamine in prefrontal cortex of rat: a potential mechanism for efficacy in attention deficit/hyperactivity disorder. Neuropsychopharmacology. 2002;27:699-711.

24. Herrera-Guzmán I, Gudayol-Ferré E, Herrera-Abarca JE, et al. Major Depressive Disorder in recovery and neuropsychological functioning: effects of selective serotonin reuptake inhibitor and dual inhibitor depression treatments on residual cognitive deficits in patients with Major Depressive Disorder in recovery. J Affect Disord. 2010;123: $341-350$.

25. Itoi K, Sugimoto N. The brainstem noradrenergic systems in stress, anxiety and depression. J Neuroendocrinol. 2010;22:355-361.

26. Hains AB, Arnsten AF. Molecular mechanisms of stress-induced prefrontal cortical impairment: implications for mental illness. Learn Mem. 2008;15:551-564.

27. Stahl SM, Grady MM, Moret C, Briley M. SNRIs: their pharmacology, clinical efficacy, and tolerability in comparison with other classes of antidepressants. CNS Spectr. 2005;10:732-747.
28. Moojen VK, Martins MR, Reinke A, et al. Effects of milnacipran in animal models of anxiety and memory. Neurochem Res. 2006;31: 571-577.

29. Selitskiı̌ GV, Kaprin AD, Izvozchikov SB, Bolotov AV, Troshina AV. Milnacipran (ixel) in the treatment of anxiodepressive and sexual disorders in patients with noninflammatory syndrome of chronic pelvic pain. Ter Arkh. 2007;79:81-84.

30. Gama CS, Zanatto VC, Picon F, Lobato MI, Belmonte-de-Abreu PS. Efficacy of milnacipran in treating anxiety symptoms in schizophrenic patients receiving clozapine: a case series study. Rev Bras Psiquiatr. 2006;28:339-340

31. Morilak DA, Frazer A. Antidepressants and brain monoaminergic systems: a dimensional approach to understanding their behavioural effects in depression and anxiety disorders. International Journal of Neuropsychopharmacology. 2004;7:193-218.

32. Szabo ST, Blier P. Functional and pharmacological characterization of the modulatory role of serotonin on the firing activity of locus coeruleus norepinephrine neurons. Brain Res. 2001;922:9-20.

33. Parini S, Renoldi G, Battaglia A, Invernizzi RW. Chronic reboxetine desensitizes terminal but not somatodendritic alpha2-adrenoceptors controlling noradrenaline release in the rat dorsal hippocampus. Neuropsychopharmacology. 2005;30:1048-1055.

34. Crews FT, Smith CB. Presynaptic alpha-receptor subsensitivity after long-term antidepressant treatment. Science. 1978;202:322-324.

35. McMillen BA, Warnack W, German DC, Shore PA. Effects of chronic desipramine treatment on rat brain noradrenergic responses to alphaadrenergic drugs. Eur J Pharmacol. 1980;61:239-246.

36. El Mansari M, Guiard BP, Chernoloz O, Ghanbari R, Katz N, Blier P. Relevance of norepinephrine-dopamine interactions in the treatment of major depressive disorder. CNS Neurosci Ther. 2010;16:e1-e17.

37. Arnsten AF, Li BM. Neurobiology of executive functions: catecholamine influences on prefrontal cortical functions. Biol Psychiatry. 2005;57: $1377-1384$.
Neuropsychiatric Disease and Treatment

\section{Publish your work in this journal}

Neuropsychiatric Disease and Treatment is an international, peerreviewed journal of clinical therapeutics and pharmacology focusing on concise rapid reporting of clinical or pre-clinical studies on a range of neuropsychiatric and neurological disorders. This journal is indexed on PubMed Central, the 'PsycINFO' database and CAS, and is the official

\section{Dovepress}

journal of The International Neuropsychiatric Association (INA). The manuscript management system is completely online and includes a very quick and fair peer-review system, which is all easy to use. Visit http://www.dovepress.com/testimonials.php to read real quotes from published authors. 